Mungai, K. \& Bayat, A. (2018). High-functioning depression among women in South Africa: An exploratory study.

Journal of Psychology in Africa, 28(5): 411-415.

http://dx.doi.org/10.1080/14330237.2018.1523312

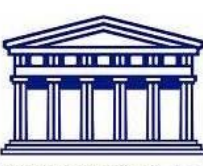

UNIVERSITY of the WESTERN CAPE

\title{
High-functioning depression among women in South Africa: An exploratory study
}

Kinyanjui Mungai and Amiena Bayat

\begin{abstract}
The study estimated the prevalence and trends of chronic depressive symptoms among women in South Africa from the National Income Dynamics Study (NIDS) data collection waves (2008, 2010, 2012, 2014/2015). NIDS utilised the Center for Epidemiological Studies Depression (CES-D) scale to assess depressive symptoms among adults. From the trend analysis, we observed a decrease in self-reported significant depressive symptoms over the eight-year period in black women (2.66\%), followed by mixed-race (coloured) women (1 $.15 \%)$. Across race, significant depressive symptoms were associated with socioeconomic status variables such as income, education, and occupational status. Within race, prevalence rates were higher among individuals with low socioeconomic status (lower income, less educated, and less skilled occupations). Black women were at a higher risk of exhibiting highfunctioning depression due to their overrepresentation among low socioeconomic stats individuals. Symptom prevalence may be explained largely by psychosocial stressors in patriarchal legacy communities.
\end{abstract}

\section{Introduction}

According to the American Psychiatric Association (APA), depression is typically defined through its symptoms, such as a depressed mood, loss of interest, low appetite, an inability to concentrate, insomnia/hypersomnia, and fatigue and may be present with suicidal thoughts (APA, 2013). Global health estimates by the World Health Organization (WHO: 2017) indicate that in 2015, depression affected an estimated $4.4 \%$ of the world population, mostly women (5.1\%). Further estimates indicate that $1.9 \%$ of people have dysthymia or high-functioning depression (Charlson, Ferrari, Flaxman, \& Whiteford, 2013). In developed countries such as the United States (USA), the prevalence of persistent depressive disorder (dysthymia) and chronic major depression are $0.5 \%$ and $1.5 \%$, respectively (APA, 2013). The prevalence of major depression is quite high in the USA at around 6.7\% (Center for Behavioral Health Statistics and Quality, 2017). The estimated prevalence of major depression using data from the South African Stress and Health Study is $4.9 \%$ of the population (Tomlinson, Grimsrud, Stein, Williams, \& Myer, 2009). On the other hand, in developing countries such as South Africa communicable diseases tend to be more prevalent, and to be studied more intensively than mental health conditions. The influence of 
depressive symptoms on personal functioning in developing country settings is in need of study.

Gender is a significant vulnerability for depressive symptoms. For instance, there is evidence to suggest that, as a result of biological factors, women have higher biological vulnerability to depression compared to men (Albert, 2015; Girgus \& Yang, 2015; WHO, 2002). Periods of hormonal changes in women during puberty, post-partum, and perimenopause are associated with increased vulnerability for major depression (Albert, 2015; Girgus \& Yang, 2015). Furthermore, environmental factors such as prolonged exposure to violence, poverty, domestic abuse, and sexual violence disproportionately increase risks for depression in women relative to men (WHO, 2002). These environmental factors vary in their salience by socio-cultural context. As examples, the South African National Burden of Disease Study 2000, indicate that unipolar (major) depressive disorders contributed $5.8 \%$ to the burden of disease in South Africa (Norman, Bradshaw, Schneider, Pieterse, \& Groenewald, 2006). The South African Stress and Health Study (2002-2004) reported a major depression life-time prevalence rate of $9.8 \%$ (Stein, Seedat, Herman, Moomal, Heeringa, Kessler, \& Williams, 2008). This study was conducted roughly a decade after the end of Apartheid, which was a system that created disparate social conditions among the South African populations framed by official racism.

In terms of point prevalence, approximately $16.1 \%$ of socio-economically deprived women exhibited depression symptoms. The life-time statistics are even higher at $33.2 \%$ for socioeconomically deprived women (Andersson et al., 2013). Even though it may be important for understanding the daily functioning of individuals, it is unclear from the literature how common high-functioning depression (or dysthymia) is in South Africa. High-functioning depression/persistent depressive disorder refers to a depressed mood for at least two years, for more days than not, for most of the day (APA, 2013). Bhagwanjee, Parekh, Paruk, Petersen, and Subedar (1998) reported that the prevalence rate of dysthymia (7.3\%) exceeded that of major depressive disorder (4.8\%). People with high-functioning depression may be regarded as those who chronically exhibit significant depressive symptoms (SDS). SDS refers to depressive symptoms that exceed the threshold of 10 using the CES-D 10 (Vogelzangs et al., 2010).

\section{Study goal}

This study aims to fill this gap by estimating the trends and prevalence of highfunctioning depression among historically deprived South African women. It sought to address the following question: What are the social risk factors affecting female vulnerability to high-functioning depression in South Africa?

\section{Method}

\section{Sources of data}

For this study, we utilised panel wave data from the South African National Income Dynamic Study (NIDS): wave 1 (2008), wave 2 (2010-2011), wave 3 (2012), and wave 4 (2014-2015). The NIDS data were collected from a nationally representative sample at both 
individual and household levels. This study only considered respondents who were 18 years of age or older at the time of the interview. Table 1 describes the sample characteristics .

\section{Measures}

Depressive symptoms were assessed using the 10- item version of the Center for Epidemiological Studies Depression Scale (CES-D; Radloff, 1977). The scale is scored on a 4-point Likert scale. The scale indicates the frequency of experiencing depression symptoms ranging from ( $1=$ rarely or none of the time (less than 1 day)), to (4= all of the time (5-7days)). A total score of ten or higher would indicate the occurrence of significant depressive symptoms. In the present study, scores from the CES-D achieved a Cronbach's alpha of 0.76 .

Since high-functioning depression is considered as having SDS (a depressive episode) for at least two years, we used this definition to measure the chronicity of depression by categorising the depressive episodes into three high-functioning depressive episodes; namely episode 1 (SDS in wave 1 and 2), episode 2 (SDS in waves 2 and 3), and episode 3 (SDS in waves 3 and 4 ).

\section{Data analysis}

For the data analysis, we utilised both descriptive analysis and regression analysis to assess the association between socio-demographics and chronic, significant depressive symptoms. Furthermore, we applied a probit analysis to assess the percentage probabilities of black women experiencing each of the ten CES-D depressive symptoms.

\section{Results}

Table 2 indicates the first chronic SDS episode measurement. This study estimates that roughly $10.47 \%$ of the participants were at risk of having high- functioning depression. ${ }^{1}$ The second chronic SDS episode measurement was lower with $7.78 \%$ (waves 2 and 3;2010 and 2012) of the study participants being at risk of having high-functioning depression. The third measured episode of chronic SDS was marginally lower with $7.69 \%$ (waves 3 and 4; 2012 and 2014/2015) of participants reporting chronic SDS.

There is a positive but weak correlation between chronic SDS across waves (see Table 3). For instance, there was a positive correlation (o .3541) between individuals who exhibited SDS between the first two (2008-2010) waves and the subsequent two waves (2010-2012). This finding suggests the chronic nature of depression.

\section{Intersections between race and gender}

Black South African women made up the largest proportion (62.21\%) of adults reporting SDS between waves 1 and 2. There was a decline in the share of black South African females self-reporting with SDS from 62.21\% (2008-2010) to 60.34\% (2010$2012)$ to $56.89 \%(2012-2014 / 2015)$ across the waves of the data. A similar trend across data waves occurred for Asian/Indian females (2.78\%-0 .59\%; 2008-2010 to 2012-2014/2015), and white females $(2.18 \%-1.53 \%$; 2008-2010 to 2012-2014/2015). 
Table 1. Sample characteristics

\begin{tabular}{|c|c|c|c|c|c|c|c|c|}
\hline & \multicolumn{2}{|c|}{ Wave 1} & \multicolumn{2}{|c|}{ Wave 2} & \multicolumn{2}{|c|}{ Wave 3} & \multicolumn{2}{|c|}{ Wave 4} \\
\hline & $n$ & $\begin{array}{l}\text { Proportion/ } \\
\text { Mean (SD) }\end{array}$ & $n$ & $\begin{array}{l}\text { Proportion/ } \\
\text { Mean (SD) }\end{array}$ & $n$ & $\begin{array}{l}\text { Proportion/ } \\
\text { Mean (SD) }\end{array}$ & $n$ & $\begin{array}{l}\text { Proportion/ } \\
\text { Mean (SD) }\end{array}$ \\
\hline Female & 6038 & $56.61 \%$ & 8533 & $54.33 \%$ & 9129 & $54.68 \%$ & 7781 & $53.97 \%$ \\
\hline Male & 7878 & $43.39 \%$ & 7172 & $45.67 \%$ & 7568 & $45.32 \%$ & 6637 & $46.03 \%$ \\
\hline Black/African & 12606 & $75.77 \%$ & 13225 & $76.44 \%$ & 15090 & $77.26 \%$ & 17355 & $77.60 \%$ \\
\hline Coloured & 1569 & $9.43 \%$ & 1624 & $9.39 \%$ & 1834 & $9.39 \%$ & 2086 & $9.32 \%$ \\
\hline Indian/Asian & 476 & $2.86 \%$ & 503 & $2.91 \%$ & 561 & $2.90 \%$ & 645 & $2.89 \%$ \\
\hline White & 1986 & $11.94 \%$ & 1949 & $11.26 \%$ & 2047 & $10.48 \%$ & 2278 & $1.19 \%$ \\
\hline No education & 1625 & $9.77 \%$ & 1395 & $8.06 \%$ & 1497 & $7.67 \%$ & 1364 & $6.10 \%$ \\
\hline Primary school & 3129 & $18.80 \%$ & 2938 & $16.98 \%$ & 3152 & $16.13 \%$ & 3299 & $14.75 \%$ \\
\hline Secondary school & 9813 & $58.98 \%$ & 1467 & $60.50 \%$ & 11863 & $60.73 \%$ & 13718 & $61.33 \%$ \\
\hline Higher education & 2070 & $12.45 \%$ & 2502 & $14.46 \%$ & 3022 & $15.47 \%$ & 3987 & $17.81 \%$ \\
\hline Per capita monthly income (Rand) & 7269 & $\begin{array}{l}3207.46 \\
(6561.57)\end{array}$ & 6763 & $\begin{array}{c}5058.11 \\
(321668.30)\end{array}$ & 8081 & $\begin{array}{c}3617.02 \\
(6146.20)\end{array}$ & 9591 & $\begin{array}{c}4126.23 \\
(11936.61)\end{array}$ \\
\hline $18-39$ years & 9899 & $59.44 \%$ & 10243 & $59.20 \%$ & 11484 & $58.79 \%$ & 13134 & $58.73 \%$ \\
\hline $40-59$ years & 4802 & $28.86 \%$ & 4995 & $28.87 \%$ & 5645 & $28.90 \%$ & 6436 & $28.78 \%$ \\
\hline $60-79$ years & 1771 & $10.64 \%$ & 1878 & $10.85 \%$ & 2187 & $11.17 \%$ & 2519 & $11.26 \%$ \\
\hline 80 years and above & 176 & $1.06 \%$ & 186 & $1.07 \%$ & 223 & $1.14 \%$ & 276 & $1.23 \%$ \\
\hline Married/living with partner & 6234 & $44.94 \%$ & 6401 & $40.92 \%$ & 6403 & $38.37 \%$ & 8262 & $37.07 \%$ \\
\hline Never married & 6065 & $43.74 \%$ & 7710 & $49.28 \%$ & 8545 & $51.21 \%$ & 11544 & $51.80 \%$ \\
\hline Widowed & 1062 & $7.66 \%$ & 1077 & $6.89 \%$ & 1215 & $7.28 \%$ & 1775 & $7.96 \%$ \\
\hline Divorced/Separated & 508 & $3.66 \%$ & 465 & $2.92 \%$ & 524 & $3.14 \%$ & 707 & $3.17 \%$ \\
\hline
\end{tabular}

Table 2. The table indicates the proportion of women who were suspected of being susceptible to having a chronic form of SDS

\begin{tabular}{lccccc}
\hline Variable & Observations & Proportion & Std error & \multicolumn{2}{c}{$95 \%$ Confidence interval } \\
\hline Chronic SDS Female Wave 1 and 2 & 7710 & 0.1047 & 0.0064 & 0.0922 & 0.1172 \\
Chronic SDS Female Wave 2 and 3 & 8340 & 0.0778 & 0.0050 & 0.0679 & 0.0876 \\
Chronic SDS Female Wave 3 and 4 & 10740 & 0.0769 & 0.0048 & 0.0674 & 0.0863 \\
\hline
\end{tabular}

Source: NIDS 2008, 2010, 2012 and 2014/2015 (author's own calculations)

Table 3. Pairwise correlation of chronic SDS women

\begin{tabular}{lccc}
\hline Variables & $\begin{array}{c}\text { Chronic SDS Female } \\
\text { Wave 1 and 2 }\end{array}$ & $\begin{array}{c}\text { Chronic SDS Female } \\
\text { Wave 2 and 3 }\end{array}$ & $\begin{array}{c}\text { Chronic SDS Female } \\
\text { Wave 3 and 4 }\end{array}$ \\
\hline Chronic SDS Female Wave 1 and 2 & 1.000 & & 1.000 \\
Chronic SDS Female Wave 2 and 3 & $0.3541^{*}$ & $0.2666^{*}$ & 1.000 \\
Chronic SDS Female Wave 3 and 4 & $0.0325^{*}$ & \\
\hline
\end{tabular}

Note. ${ }^{*}$ shows significance at the .05 level

Source: NIDS 2008, 2010, 2012 and 2014/2015 (author's own calculations) 
Table 4. Probit regression on Black African females using the CES-D (Average partial effect)

\begin{tabular}{|c|c|c|}
\hline Predictors & Coefficients & Std error \\
\hline Bothered & -0.0230 & 0.0417 \\
\hline Trouble focusing & -0.0573 & 0.0433 \\
\hline Depressed & 0.0280 & 0.0329 \\
\hline Everything an effort & -0.0364 & 0.0243 \\
\hline Not hopeful about future & -0.0410 & 0.0239 \\
\hline Felt fearful & $0.0999 * * *$ & 0.0343 \\
\hline Restless sleep & 0.0399 & 0.0289 \\
\hline Not happy & $0.0530 * *$ & 0.0249 \\
\hline Felt lonely & -0.0398 & 0.0321 \\
\hline Could not get going & 0.0583 & 0.0352 \\
\hline \multicolumn{3}{|c|}{$\begin{array}{l}\text { Note. }{ }^{*} p<0.05 ; * * p<0.01 ; n=642 ; \text { Prob }>\text { Chi-squared }=0.0063(\mathrm{Th} \\
p \text {-value is small, therefore at least one of the regression coefficients is } \\
\text { not equal to zero); Pseudo } \mathrm{R}^{2}=0.0624 \\
\text { Source: Author's own calculations using NIDS } 2008 \text { and } 2014 / 2015 \\
\text { data. }\end{array}$} \\
\hline
\end{tabular}

Table 4 represents a probit regression indicating the probability of the ten depressive symptoms experienced by black South African females using the CES-D tool. If the frequency of feeling fearful increased by one unit, the probability that the adult was a black female increased by ten percentage points, holding other factors constant. The data in Table 4 suggest high prevalence of high-functioning depressive symptoms among black South African women $(p<0$.01). If the frequency of feeling unhappy increased by one unit, the probability that the adult was a black female increased by 5.30 percentage points, holding other factors constant. The data on feelings of unhappiness were statistically significant among black women $(p<0.05)$.

\section{Neighbourhood and personal factors}

Regression 1 (in Table 5) presents probability estimates of females, self-reporting SDS between 2010 and 2012, experiencing a host of events. The results indicate that women with chronic SDS were 2.23 percentage points more likely to feel that neighbourhood theft was a common occurrence, which would explain their sense of chronic depression. Similarly, regression 2 indicates that women experiencing chronic SDS were $1 \quad .92$ percentage points more likely to feel that neighbourhood gang activity was a common occurrence. This finding was consistent between waves 3 and 4 (regression 3), where 3 
$.18 \%$ of chronic SDS women felt that the occurrence of gang activities was common in their neighbourhood. This further underscores the point that depressive symptoms tend to persist among women living in disadvantaged neighbourhoods, where there are high levels of crime, violence, and victimisation of vulnerable groups like women.

Table 5. Probit regression on neighbourhood factors risk factors for chronic SDS women

\begin{tabular}{lccc}
\hline Average marginal effects & $\begin{array}{c}\text { Chronic SDS Female } \\
\text { Wave 1 and 2 }\end{array}$ & $\begin{array}{c}\text { Chronic SDS Female } \\
\text { Wave 2 and 3 }\end{array}$ & $\begin{array}{c}\text { Chronic SDS Female } \\
\text { Wave 3 and 4 }\end{array}$ \\
\hline Trust neighbour & -0.0187 & 0.0105 & 0.0269 \\
& $(0.0102)$ & $(0.0094)$ & $(0.0155)$ \\
Trust stranger & -0.0538 & 0.0264 & $0.0685^{* * *}$ \\
& $(0.0354)$ & $(0.0193)$ & $(0.2892)$ \\
Neighbourhood theft & $0.0223^{* *}$ & 0.0140 & 0.0007 \\
& $(0.0103)$ & $(0.0073)$ & $(0.0062)$ \\
Importance of religion & 0.0069 & 0.009 & 0.0050 \\
& $(0.0116)$ & $(0.0059)$ & $(0.0054)$ \\
Neighbourhood gang activities & N/A & $0.0192^{* *}$ & $0.0318^{* * *} *$ \\
Observations & 7710 & 8340 & $(0.0076)$ \\
\end{tabular}

Note. Standard errors are in parenthesis; ${ }^{* * *} p<0.01,{ }^{*} p<0.05$

Source: NIDS 2008, 2010, 2012 and 2014/2015 (author's own calculations)

Although this study is unable to indicate how living in such neighbourhoods affects the ability of women to access mental health treatment, it could intuitively be hypothesised that their social environment does have some bearing on mental health access. Interestingly, the results indicate that females with chronic SDS are particularly trusting. It is estimated that chronic SDS females were 6.85 percentage points more likely to be trusting of strangers. This is particularly interesting, as it may seem counterintuitive that black South African women are trusting towards strangers whilst residing in socially in- cohesive, crime ridden, low trust communities. It may also be that a stranger (male or female), who does not live in their community may by default appear to be a more trustworthy counterpart in contrast to people who live in the same disheartening environment as themselves, who have proved to be untrustworthy .

\section{Discussion and conclusion}

The study found that the prevalence of chronic SDS among women in South Africa has decreased over the periods 2008 to 2014/2015. This decline has been particularly significant among the Asian/Indian and white population groups. Yet, we caution this finding as the Asian female sample was below 100 for all the years (and may thus not be representative). Similarly, the white female sample was between 100-200 respondents for the analysis (and may thus not be representative). Among women from historically disadvantaged communities, who primarily are mixed-race and black women, the results suggest initial declines (from the first to the second measured chronic SDS episode) of 1 $.9 \%$ and $2.88 \%$ in the prevalence, respectively. From the second to the third measured episode of chronic SDS, there was a slight increase in the prevalence rates for mixed-race women $(0.75 \%)$ and black women $(0.22 \%)$. Overall the prevalence of high- functioning 
depression in a significant proportion of black and mixed-race women may be indicative of their unchanging social, economic, and personal circumstances.

There are a number of reasons why black South African females may be more susceptible to chronic depression. At the systemic level, the intersectionality of racial and gender subordination (Crenshaw, 1989) in post-Apartheid South Africa and historical legacies of patriarchy may explain the findings of this study. More specifically, women have less economic and social power in South Africa than males and carry heavy family responsibilities. In fact, compared to non-lone mothers, more women in South Africa are likely to be lonemothers. They thus have to juggle family and work responsibilities, sometimes without any support from the father (Wright, Noble, Ntshongwana, Neves \& Barnes, 2013). These groups of women (more often mixed race and black women) are further disadvantaged by living in neighbourhoods characterised by crime and gangsterism, where they often live in fear. The intersectionality of racial and gender subordination (Crenshaw, 1989) in postApartheid South Africa and historical legacies of patriarchy may explain the findings of this study. This social condition is germane to the discussion on women's mental health in the South African context, as it is widely cited that living in poverty and facing neighbourhood violence exacerbates depressive symptoms (Dinan, Mccall, \& Gibson, 2004; Moodley, 2012, 2014; Segalo, 2015).

\section{Study limitations}

Limitations of the study include the use of the self-reported data which may be confounded by under-reporting or over- reporting of symptoms. For that reason, the study results should be interpreted with caution. Second, wave 2 had high non-response rates. Thirdly, the South African Asian/ Indians were underrepresented in the sample. Fourth, a recall bias may exist as a result of the stigma attached to mental disorders such as depression. Future studies could focus on populations that are well represented in the NIDS study rather than attempting to encompass all the population groups in the study. In addition, future studies should not limit themselves by feeling the need to use all the NIDS waves. It is sufficient to exclude wave 2 (due to high non-response rates) and just focus on waves 3 and 4 which have less attrition, and less item levelnon-response.

\section{Conclusion}

In conclusion, we found the prevalence rate of chronic high- functioning depression among women to have marginally steadily decreased over the years, although significantly present among women from historically disadvantaged communities. Living in rough neighbourhoods and personal factors explained the prevalence of chronic SDS among the women due to feelings of fear and unhappiness. Persistent economic hardships may further exacerbate these depressive symptoms among women from disadvantaged communities . 


\section{Endnotes}

1 Being at risk of having an SDS episode would be regarded as individuals who meet or exceeded the CES-D 10 threshold. We refer to the individual being at-risk of chronic/persis- tent/high-functioning SDS if this occurs in two consecutive waves. Therefore the first chronic SDS episode was defined and measured as adults exhibiting significant depressive symptoms in both waves 1 and 2 (2008 and 2010)

\section{References}

Albert, P . R . (2015) . Why is depression more prevalent in women? JPN, 4O(4), 219221. https://doi .org/10 .1503/ jpn .150205 PMID:26107348

American Psychiatric Association . (2013) . Diagnostic and statistical manual of mental disorders (5th ed.). Arlington, VA: American Psychiatric Publishing .

Andersson, L. M., Schierenbeck, I ., Strumpher, J ., Krantz, G., Topper, K., Backman, G., . .. Van Rooyen, D. (2013). Help-seeking behaviour, barriers to care and experiences of care among persons with depression in Eastern Cape, South Africa . Journal of Affective Disorders, 151(2), 439-448 . https://doi .org/10 .1016/j .jad .2013.06 .022 PMID:23890669

Bhagwanjee, A., Parekh, A., Paruk,Z ., Petersen, I ., \& Subedar, H. (1998). Prevalence of minor psychiatric disorders in an adult African rural community in South Africa . Psychological Medicine, 28(5), 1137-1147 . https://doi .org/10 .1017/ So033291798006965 PMID:9794021

Burns, J. K. (2011). The mental health gap in South Africa: A human rights issue . The Equal Rights Review, 6(99), 99-113 . qualrightstrust .org/ertdocumentbank/ERRo6_special_Jonathan .pdf

Center for Behavioral Health Statistics and Quality . (2017) . 2016 National Survey on Drug Use and Health: Methodological summary and definitions . Rockville, MD: Substance Abuse and Mental Health Services Administration .

Charlson, F . J ., Ferrari, A . J ., Flaxman, A . D ., \& Whiteford, H . A . (2013) . The epidemiological modelling of dysthymia: Application for the Global Burden of Disease Study 2010 . Journal of Affective Disorders, 151(1), 111-120 . https://doi . org/10 .1016/j .jad .2013.05 .060 PMID:23806588

Crenshaw, K . (1989). Demarginalizing the intersection of race and sex: A Black feminist critique of antidiscrimination doctrine, feminist theory, and antiracist politics . University of Chicago Legal Forum, 1989(1), 139-167 . https://chicagounbound .uchicago. edu/cgi/viewcontent . cgi?article $=1052 \&$ context $=$ uclf

Dinan, B . A ., McCall, G . J ., \& Gibson, D . (2004). Community violence and PTSD in selected South African townships. Journal of Interpersonal Violence, 19(6), 727742. https:// doi .org/10 .1177/0886260504263869 PMID:15140321

Girgus, J . S ., \& Yang, K. (2015). Gender and depression . Current Opinion in Psychology, 4, 53-60. https://doi.org/10.1016/j. copsyc .2015.01.019

Lorant, V., Deliège, D ., Eaton, W., Robert, A., Philippot, P ., \& Ansseau, M . (2003) . Socioeconomic inequalities in depression: A meta-analysis . American Journal of Epidemiology, 157(2), 98-112. https://doi.org/10.1093/aje/ kwf182 PMID:12522017 
McKenna, M. T ., Michaud, C. M ., Murray, C . J ., \& Marks, J . S . (2005). Assessing the burden of disease in the United States using disability-adjusted life years . American Journal of Preventive Medicine, 28(5), 415-423 . https://doi . org/10 $.1016 / j$.amepre .2005 02 .009 PMID:15894144

Moodley, J. (2012). The effects of selected socio-demographic variables on depression and resilience in a sample of socio-economically disadvantaged women in Doornkop, Soweto (Unpublished doctoral dissertation) . University of Johannesburg, Johannesburg .

Moodley, J . (2014) . Women's mental health: Coping mechanisms in the context of poverty . Journal of Psychology in Africa, 24(3), 264-271 . https://doi.org/10.1080/14330237 .2014 .906078

Norman, R ., Bradshaw, D ., Schneider, M ., Pieterse, D ., \& Groenewald, P . (2006) . Revised Burden of Disease Estimates for the Comparative Risk Factor Assessment, South Africa 200o. Methodological Note. Cape Town: South African Medical Research Council .

Radloff, L . S . (1977). The CES-D scale: A self-report depression scale for research in the general population . Applied Psychological Measurement, 1(3), 385-401 . https://doi . org/10 .1177/014662167700100306

Segalo, P. (2015). Gender, social cohesion and everyday struggles in South Africa. Psychology in Society, (49), 70-82. http:// www .scielo .org .za/pdf/pins/n49/o6 .pdf

Stein, D. J ., Seedat, S ., Herman, A., Moomal, H ., Heeringa, S. G., Kessler, R. C., \& Williams, D. R. (2008). Lifetime prevalence of psychiatric disorders in South Africa . The British Journal of Psychiatry, 192(2), 112-117. https://doi . org/10.1192/bjp .bp .106 .029280 PMID:18245026

Tomita, A ., Labys, C . A., \& Burns, J. K. (2015) . A multilevel analysis of the relationship between neighborhood social disorder and depressive symptoms: Evidence from the South African National Income Dynamics Study . The American Journal of Orthopsychiatry, 85(1), 56-62 . https://doi . org/10 .1037/ortoooo049 PMID:25642654

Vogelzangs, N., Kritchevsky, S. B., Beekman, A. T ., Brenes, G. A., Newman, A. B., Satterfield, S ., . . . Penninx, B . W . (2010) . Obesity and onset of significant depressive symptoms: Results from a community-based cohort of older men and women. The Journal of Clinical Psychiatry, 71(4), 391-399 . https://doi .org/10 .4088/JCP .08m04743blu PMID:20021992

Williams, D. R., Herman, A., Stein, D. J., Heeringa, S. G., Jackson, P. B., Moomal, H., \& Kessler, R. C . (2008). Twelve-month mental disorders in South Africa: Prevalence, service use and demographic correlates in the population- based South African Stress and Health Study . Psychological Medicine, 38(2), 211-220 . https://doi .org/10 .1017/ So033291707001420 PMID:17903333

World Health Organization . (2002) . Gender and mental health. Geneva: World Health Organization .

World Health Organization. (2017). Depression and other common mental disorders: global health estimates. Geneva: World Health Organization . 
Wright, G ., Noble, M ., Ntshongwana, P ., Neves, D ., \& Barnes, H. (2013). Themed Working Paper 1: Defining Lone Motherhood in South Africa. Retrieved from http://default/files/publications-pdf/LM\%20TWP1_Lone_Mothers_in_SA .pdf 